\title{
The Philip's Curve in Sub-Saharan Africa: Evidence from Panel Data Analysis
}

\author{
Godwin Essang Esu, Johnson Akpan Atan \\ Department of Economics, Faculty of Social Sciences, University of Uyo, Uyo, Nigeria \\ Email address: \\ esugodwin1@gmail.com (G. E. Esu),johnsonatan@yahoo.com(J. A. Atan)
}

\section{To cite this article:}

Godwin Essang Esu, Johnson Akpan Atan. The Philip's Curve in Sub-Saharan Africa: Evidence from Panel Data Analysis. Journal of World Economic Research. Vol. 6, No. 5, 2017, pp. 59-66. doi: 10.11648/j.jwer.20170605.11

Received: November 25, 2017; Accepted: December 5, 2017; Published: December 25, 2017

\begin{abstract}
In this study, we attempted the assessment of the validity of the Philip's curve hypothesis in the Sub-Saharan African region. We employed a panel data technique of analysis, drawing data from twenty-nine countries in the region. The data spanned 24 years (1991 to 2015). The inflation rate was captured using the consumer price index (CPI - its log first difference), while unemployment rate was measured by total unemployment (as a percentage of total labour force, a national estimate). Using a panel data analysis technique, our result showed that there was no significant relationship between inflation rate and the rate of unemployment (based on Two-Way FE), but One-Way FE and RE showed a rather significant trade-off. Though the conflicting results suggest an inconclusive outcome, the Two-Way FE (that was the technique in focus in this study), seems to invalidate the existence of the common Philip's Curve (that is, unemployment-inflation trade-off) in the SubSaharan African region.
\end{abstract}

Keywords: Philip’s Curve, Inflation, Unemployment, Economic Policy, Trade-off

\section{Introduction}

Macroeconomic policies are implemented in order to achieve government's main objectives of full employment and stable economy through low inflation. "Philips Curve" has been seen as a tool to explaining the trade-off between these two objectives. The literature is flooded with different researches and conclusions on the issue of unemploymentinflation trade-offs, since the hypothesis of William Philips (the inverse relationship between unemployment and inflation, that has come to be known has "The Philips Curve") in 1958. Despite the criticisms that have trailed the Philips curve hypothesis, all the arguments about the tradeoffs seems to draw their basis from the "the Philips argument".

Hart (2003) observes that the Philips Curve still plays an outstanding role in macroeconomics theory and associated empirical investigations. The importance of this hypothesis may not be disassociated from the unavoidable role of unemployment and inflation in the stability or otherwise of the macroeconomic setting of any economy. Moreover, there has been diverse explanations to the operation of the Philips Curve hypothesis, to foster common understanding of the implication of the hypothesis. The basic understanding of the Philips Curve can, therefore, be drawn from the interaction between labour demand and supply. If there is excess of labour demand over supply, pressure on wage rate may fuel high inflation, but finding employment may be easy, ceteris paribus.

On the other hand, if there is increase in the supply of labour over demand of same, pressure on wage rate is expected to fall, resulting in a fall in inflation rate. However, this may result in a rise in unemployment level. In other words, unemployment and inflation rates rise, in the shortrun, is caused either by negative shocks to aggregate supply as that occurred during the oil crises of 1970 or by negative shocks to the aggregate demand such as occurred, due to contractionary monetary or fiscal policies in 1980 and early 1990 s, as was evident in majority of OECD economies (Bhattarai, 2004).

It is also evident, over the years, that amidst criticisms that have trailed the Philips Curve hypothesis, many macroeconomic policy find-tuning have revolved around how different policy makers, institutions and the public, react to the outcome of this hypothesis across economies (Islam, Mustafa and Rahman, 2003). In other words, despite the 
controversies in the literature, varying rate of unemployment across countries over time is one of the major economic issues and draws overwhelming concerns of public and policy makers around the world (Bhattarai, 2004).

In sub-Saharan Africa, one of the greatest challenges facing development in it economies, has been the issues of persistent rise in the rate of unemployment and inflation and the continuous drop in wage rate. Perhaps, this may have fueled the persistent rise in poverty rate, infant mortality, continuous drop in healthcare, standard of living, and so on. The major motivation for this research, therefore, is the fact that most investigations on the Philips curve hypothesis - in the African context - has been country-specific, employing time series data at different lags and the results so far has been mixed, but not much (if any) has been done using panel data approach. This work attempts a cover for this gap.

\section{Literature Review}

The year 1958 brought a landmark turnaround in the history of economic theorizing, when William Philips published his controversial seminal entitled "The Relationship between Unemployment and the Rate of Change of Money Wage Rates in the United Kingdom" in the London School of Economics' journal, Economica (Philips, 1958). This work was a very significant contribution to economic thought. In his findings, that later became "The Philips Curve Hypothesis", William Philips, argued that there is a strong negative relationship between unemployment and inflation, drawing his inferences from UK data (1861 1957). Since then, there had been curious researches by researchers to validate or refute this conclusion. Two American economists (Paul Samuelson and Robert Solow) were quick to test for the validation of Philips' argument, and their outcome supported the stance of Philips (Samuelson and Solow, 1960).

Solow (1970) and Gordon (1971) further affirmed the existence of negative trade-offs between unemployment and inflation in the United States, using both pre-1970s and post1970s data. As Furuoka and Munir (2009) observed, the findings were later known as the "Solow-Gordon affirmation" of the Phillips curve hypothesis. The strong theoretical stance and empirical support notwithstanding, "Phillips curve" hypothesis have suffered strong criticism since in the 1960s. This was observed by Islam et al. (2003) when he argued that, since inception, the hypothesis had been a subject of strong debate. Friedman (1968) and phelps (1968) led the attack. The elation about the Phillips curve debilitated after Phelps (1968) analysis of wage dynamics taking account of union's and worker's expectations about the future events in the labour market. Also, the strong argument of Friedman (1968) in support of the natural rate of unemployment hypothesis convinced many economists on the futility of monetary policy to achieve real objectives in the long run. In other words, they argued that, though there could be a negative interaction between unemployment and inflation in the short run, in the long run such trade-off disappears, that is, a state where unemployment rate moves towards equilibrium, (a situation of "natural rate of unemployment or "non-accelerating inflation rate of unemployment [NAIRU]), Cashell (2004). As could be seen in most relatively stabilized economies, only unexpected policy shocks could have tangible impacts in the economy (Lucas and Rapping, 1969). While higher and erratic rates of unemployment is still an enigma, the success recorded in stabilizing price level in most economies - especially the OECD - through inflation targeting by central banks, seems to have sustained afore argument.

Lucas (1976) further pulled a strong criticism on the existence of the "Phillips Curve". He argued that, the tradeoff could only exist if the workers are oblivious of the fact that policy makers could create artificial high-inflation-lowunemployment situation, otherwise, for fear of future inflation, demand for wage raise would be imminent. This presupposes the fact that unemployment and high inflation rate could coexist. "Lucas critique" in the 1970s created a substantial level of neglect around the Phillips curve within the sphere of academics in the 1980s, though it remains an essential tool for policy makers (Debelle and Vickery, 1998). However, in the 1990s, the interest in the Phillips curve was significantly revived among scholars (Debelle et al. 1998). Evidently, King and Watson (1994) assessed the Phillips curve (PC) hypothesis, US post-war macroeconomic data, and found a support for the existence of the trade-off, with a caveat, that this will be if and only if the log-run and shortrun noises were evacuated. Hogan (1998) also found empirical support for hypothesized negative interactions between inflation and unemployment, but emphasized the fact that traditional Phillips Curve seems to over-predict the rate of inflation.

However, there has been a methodological shift in the assessment of Phillips curve hypothesis in recent times. Researchers use panel data approach in establishing the existence or otherwise of the Phillips curve hypothesis among countries and regions. For instance, DiNardo and Moore (1999), using the methods of Ordinary Least Squares (OLS) and Generalised Least Squares (GLS), found a "common" Philips curve in nine (9) Organisation for Economic Cooperation and Development (OECD) countries. Turner and Seghezza (1999) reached a similar outcome for twenty-one (21) OECD countries, using Seemingly Unrelated Estimation (SURE) technique. As a deviant from the already established closed economy assumption of the Phillips curve hypothesis, Batini, Jackson and Nickell (2005) derived an open-economy Phillips curve from theoretical principles, but argued that the consistent estimation of parameters demands that the open-economy model be augmented by variables in the open economy.

Many other considerations and approaches have been attempted. For instance, using time series data, Tang and Lean (2007) found a stable trade-off relationship between inflation rates and unemployment rates for Malaysia. Furuoka (2007), in a related development, found a long-run relationship between the two variables, as well as a causal 
relationship between the two variables still for Malaysia. However, using time series data, Orji, Orji and Okajor (2015) found a positive relationship between the two variables for Nigeria, while Onwioduokit (2006) found a negative relationship. Ola-David and Oluwatobi (2012) also found a negative, long-run relationship between inflation and unemployment in Nigeria. Carlos (2010) did a similar work for African countries, using Nigeria as a case studies. He concluded that, though results were conflicting, Phillips curve can be a tool for inflation control, e.g. inflation targeting regime. Two things that stand out in the literature so far are (i) the conflicting outcomes in terms of the trade-off between inflation and unemployment, and (ii) the fact that much has not been done on this subject as it relates to SubSaharan African region. The third is the issue of methods and technique, hence the need for this work.

\section{Empirical Methodology}

\subsection{The Theory and the Model}

At the time, Phillips (1958) and Samuelson and Solow (1960), carried out their analysis, average inflation was close to zero during much of that period. In such circumstance, it was reasonable to form expectation about inflation to be equal to zero, that is, $\pi_{t}^{e}=0$, hence the equation:

$$
\pi_{t}=(\mu+\mathrm{z})-\alpha u_{t}
$$

Where $\pi_{t}$ represents inflation rate, $\mu$ is the markup and $z$ represents the factors that affect wage determination, $\alpha$ measures the effect of unemployment on the inflation rate, while $u$ captures the unemployment rate. Time period is captured as $t$. Equation (1) is the traditional negative relation between unemployment and inflation that Phillips identified for the United Kingdom and Solow and Samuelson found for the United States of America (original Phillips curve). However, the way with which people form expectation changed as a result of changes in inflation behavior. The rate of inflation became positive and persistent, unlike the times of Phillips, Samuelson and Solow, thus, high inflation in one year became more likely to be followed by high inflation in the next year. This situation changed the way expectation about inflation rate is formed. People could not expect the rate of inflation in the present year to be the same as the previous year. This change in expectation changed the nature of the relation between unemployment and inflation. The unemployment rate affects not the inflation rate, but the change in the inflation rate:

$$
\pi_{t}-\pi_{t-1}=(\mu+\mathrm{z})-\alpha u_{t}
$$

This modified Phillips curve (also known as the expectations-augmented Phillips curve or the accelerationist Phillips curve) is the form the Phillips curve relation between unemployment and inflation takes lately (Blanchard, 2009).

However, considering the concept of natural rate of unemployment - the unemployment rate in which the actual inflation rate is equal to the expected inflation rate Friedman (1968) and Phelps (1968) argued for the existence and the role of natural rate of unemployment in establishing unemployment-inflation relation, despite Phillips (1958)'s position on the none existence of same. Thus, denoting the natural unemployment rate by $u_{n}$ and imposing the condition that actual inflation is equal to the expected inflation rate $\left(\pi_{t}=\pi_{t}^{e}\right)$ in equation such as thus:

$$
\pi_{t}=\pi_{t}^{e}+(\mu+z)-\alpha u_{t}
$$

gives

$$
0=(\mu+z)-\alpha u_{n}
$$

Solving for the natural rate, $u_{n}$ :

$$
u_{n}=\frac{\mu+z}{\alpha}
$$

The higher the markup, $\mu$, or the higher the factors that affect wage setting, $z$, the higher the natural rate of unemployment. So, we can rewrite equation (3) as:

$$
\pi_{t}-\pi_{t}^{e}=-\alpha\left(u_{t}-\frac{\mu+z}{\alpha}\right)
$$

Since the fraction on the right-hand side of equation (6) is equal $u_{n}$, we have

$$
\pi_{t}-\pi_{t}^{e}=-\alpha\left(u_{t}-u_{n}\right)
$$

If the expected rate of inflation $\left(\pi_{t}^{e}\right)$ is well approximated by last year's inflation rate, $\left(\pi_{t-1}\right)$, as it is theoretically the case in most developed economies, example, USA, then, the equation finally becomes:

$$
\pi_{t}-\pi_{t-1}=-\alpha\left(u_{t}-u_{n}\right)
$$

Equation (8) portrays the Phillips curve as a relation between the actual unemployment rate, $u_{t}$, the natural unemployment rate, $u_{n}$, and the change in the inflation rate, $\pi_{t}-\pi_{t-1}$. In other words, the change in the inflation rate depends on the difference between the actual and the natural unemployment rates. When the actual unemployment rate is higher than the natural unemployment rate, the inflation rate decreases and vice versa. Equation (8) also shows that the natural unemployment rate is the rate of unemployment required to keep the inflation rate constant, hence the name, Non-accelerating Inflation Rate of Unemployment (NAIRU) (Blanchard, 2009 and Mankiw, 2000). The logical structure of the theorists' argument presents clearer picture in testing, to validate or otherwise, this relation for selected SubSaharan African countries, from 1991 to 2015. The annual data for unemployment rate and inflation rate for these countries are obtained from World Development Indicators (WDI) (2016). The inflation rate is captured by the consumer price index (CPI - its log first difference), while unemployment rate is measured by total unemployment (as a percentage of total labour force, a national estimate) for these countries.

\subsection{Econometric Specification}

Deducing from the theoretical underpinning so far, our set of estimation is based on the panel data regression. This 
seems a more appropriate econometric technique to process information on unemployment rate and inflation rate across countries over a period of time. It allows us to decompose country-specific and time-specific factors that influence the rate of unemployment as provided by the expectation augmented Phillips curve in Eq. (7). We use a standard balanced panel data model, popular in the econometrics literature (Hendry, 1993 and Maddalla, 2001). In this paper, therefore, we adopt a one-way and two-way fixed effects (FE) approach. The FE approach is a better approach for the situation where there is unobservable country-effects and unobservable time-effects, hence the one-way and two-way fixed effects equations:

$$
I n f l_{i t}=\delta_{i}+\vartheta_{1} U n_{i t}+\vartheta_{2} \operatorname{Infl} l_{i t-1}+\partial_{i t}
$$

A one-way FE, where $\operatorname{Infl} l_{i t}$ captures inflation rate in the country $i$ in year $t$. $U n_{i t}$ represents unemployment rate in the country $i$ in the year $t$. Infl $l_{i t-1}$ is one-year lagged values of inflation rate in the country $i$ and $\delta_{i}$ is the unobserved country-effects. $\vartheta_{1}$ and $\vartheta_{2}$ are parameters that measure the elasticities (slopes) of inflation rate and unemployment rate in country $i$, while $\partial_{i}$ captures the idiosyncratic error. Also, the two-way FE is presented thus;

$$
\text { Infl } l_{i t}=\alpha+\delta_{i}+\theta_{i}+\vartheta_{1} U n_{i t}+\vartheta_{2} I_{n} f l_{i t-1}+\partial_{i t}
$$

Where $I n f l_{i t}$ captures inflation rate in the country $i$ in year $t$. $U n_{i t}$ represents unemployment rate in the country $i$ in the year $t$. Inf $l_{i t-1}$ is one-year lagged values of inflation rate in the country $i, \alpha$ is the intercept, $\delta_{i}$ is the unobserved countryeffects and $\theta_{i}$ represents the unobserved time-effects. $\vartheta_{1}$ and $\vartheta_{2}$ are parameters that measure the elasticities (slopes) of inflation rate and unemployment rate in country $i$, while $\partial_{i}$ captures the idiosyncratic error.

It is common in the literature for researchers to apply both fixed-effect (FE) and random-effect (RE), and then formally test for statistically significant variations in the coefficients on the time-varying explanatory variables, as was first proposed by Hausman (1978). However, the prime factor that determines whether FE or RE is to be used is, whether we can reasonably assume $\delta_{i}$ is uncorrelated with the explanatory variables, say, $x_{i j}$. Nevertheless, in some applications of panel data methods, we cannot treat our sample as a random sample from a large population, especially when the unit of observation is a large geographical unit - for instance, states, cities or countries (Wooldridge, 2013). It makes sense, therefore, to think of each $\delta_{i}$ as a separate intercept to estimate for each crosssectional unit. For this course, therefore, we use fixed effects (FE). It is important to note the fact that, using FE is instinctively the same as allowing a different intercept for each cross-sectional unit. The beauty is that, whether or not we engage in the logical debate about the nature of $\delta_{i}, \mathrm{FE}$ is almost always much more convincing than RE for policy analysis using aggregated data (Wooldridge, 2013). This argument substantiates our use of two-way FE panel data method in this work, amid other related methods.

Next, a panel cointegration method is necessary to examine the long-run relationship between unemployment rate and inflation rate in selected countries of Sub-Saharan Africa. Panel cointegration tests are, relatively, an application of the Engle and Granger (1987) cointegration test to panel data (Bahmani-Oskooee and Miteza, 2004 and Furuoka and Munir, 2009). However, in this paper, we are gleaning from the suggestion of Pedroni $(1999,2004)$ for the cointegration analysis. If the independent and dependent variables are cointegrated or have a long-run relationship, the residual $\varepsilon_{i t}$, will be integrated of the order zero I (0). For this, Pedroni employs two types of panel cointegration tests: the first is "panel statistic" that is equivalent to a unit root statistic against the homogenous alternative, while the second is the "group mean" statistic that is similar to the panel unit root test against the heterogeneous alternative.

According to Pedroni (2004), the "panel statistic" can be constructed by taking the ratio of the sum of the numerators and the sum of the denominators of the analogous conventional time series statistics. The "group mean" statistic can be constructed by first computing the ratio corresponding to the predictable time series statistics and then computing the standardized sum of the entire ratio over the $N$ dimension of the panel. As suggested by Pedroni $(1999,2004)$ therefore, the two versions of panel cointegration - the "Panel ADF statistic" and the "Group mean ADF statistic" - models are presented thus:

Panel

$$
Z_{t}=\left(\tilde{s}^{2} N T \sum_{i=1}^{N} \sum_{I=1}^{T} \hat{e}^{2}{ }_{i . t-1}\right)^{-1 / 2} \sum_{i=1}^{N} \sum_{t=1}^{T} \hat{e}_{\mathrm{i} . \mathrm{t}-1} \Delta \hat{e}_{\mathrm{i} . \mathrm{t}}
$$

\section{Group Mean}

$$
N^{-1 / 2} Z_{t}=N^{-1 / 2} \sum_{i=1}^{N}\left(\sum_{t=1}^{T} \hat{S}_{\mathrm{i}} \hat{e}_{\mathrm{i}, \mathrm{t}=1}^{2}\right)^{-1 / 2} \sum_{t=1}^{T} \hat{e}_{\mathrm{i}, \mathrm{t}-1} \Delta \hat{e}_{\mathrm{i} . \mathrm{t}}
$$

Where $\hat{e}_{\text {i.t }}$ represents the residuals from the ADF estimation, $\tilde{S}_{N T}$ is the contemporaneous panel variance estimator, and $\hat{s}_{i}$ is the standard contemporaneous variance of the residuals from the ADF regression. ${ }^{1}$ The asymptotic distribution of panel and group mean statistics can be expressed in:

$$
\frac{K_{N, T}-\mu \sqrt{N}}{\sqrt{V}} \rightarrow N(0,1)
$$

Where $K_{N, T}$ is the appropriately standardized form for each of statistics, $\mu$ is the mean adjustment term and $v$ is the variance adjustment term. Pedroni (1999), according to Furuoka and Munir (2009), provides Monte Carlo estimates of $\mu$ and $v$.

However, to ascertain the need for a cointegration test, the first step is to establish the stationarity of each variable in the model. Panel unit root test could be seen as an extension of the univariate unit root test; thus, we employ the Levin - Lin - Chu (LLC) test. The LLC test is based on the pooled panel data, and according to Levin and Lin (1992), is presented as follows:

1 This article employs unweighted statistics. Pedroni (2004) argued that in Monte Carlo simulation unweighted statistics tended to outperform the weighted statistics. 


$$
\Delta y_{i t}=p y_{i . t-1}+\alpha_{0}+\delta t+\alpha_{i}+\beta_{t}+\varepsilon_{i t}
$$

Where $p, \alpha_{0}, \delta$ are coefficients, $\alpha_{i}$ is individual - specific effect, and $\beta_{i}$ is time - specific effect. Levin - Lin (1993) holds that the LLC test could follow the following steps:

1. Subtract the cross-section average from data;

$$
\bar{y}=1 /{ }_{N} \sum_{i-1}^{N} y_{i t}
$$

2. Apply an ADF test to each individual series and normalize the disturbance. The ADF model could be expressed thus:

$$
\Delta y_{i t}=p_{i} y_{i t-1}+\sum_{j=1}^{p_{i}} \pi_{i j} \Delta y_{i . t-1}+\alpha_{i}+\varepsilon_{i t}
$$

As opine by Maddala and $\mathrm{Wu}$ (1999), this is equivalent to carrying out two auxiliary regressions of $\Delta y_{i t}$ and $y_{i . t-1}$ on the remaining variable in equation (17). Let the residuals from these two regression be $\hat{e}_{i . t}$ and $\hat{V}_{i . t-1}$ respectively. Thus, regressing $\hat{e}_{i . t}$ on $\widehat{V}_{i . t-1}$ results in;

$$
\hat{e}_{i . t}=p_{i} V_{i . t-1}+\varepsilon_{i t}
$$

Levin and Lin (1993) suggest the following normalization to control the heteroscedasticity in error.

$$
\begin{gathered}
\hat{\sigma}_{e_{i}}^{2}=\frac{1}{T-P-1} \sum_{I-P+2}\left(\hat{e}_{i . t}-\hat{P}_{i} \widehat{V}_{i . t-1}\right)^{2} \\
\tilde{e}_{i, t}=\frac{\tilde{e}_{i, t}}{\hat{\sigma}_{e_{i}}} \\
\tilde{v}_{i, t-1}=\frac{\tilde{v}_{i, t-1}}{\widehat{\sigma}_{e_{i}}}
\end{gathered}
$$

Next, the LLC test statistic could be obtained from the following regression;

$$
\tilde{e}_{i, t}=\rho \tilde{v}_{i, t-1}+\tilde{\varepsilon}_{i, t}
$$

The t-statistic for testing $\delta=0$ is given as $t_{\delta}=\frac{\widehat{\delta}}{\operatorname{STD}(\widehat{\delta})}$

\section{Presentation of Results and Analysis of Findings}

\subsection{Summary Statistic}

In analyzing the data, we took first, the summary statistic of the data for unemployment and inflation for the selected Sub - Saharan African countries, cover by the scope of this research. The result is presented in Table 1. The result on the table shows that inflation in Sub-Saharan Africa growths on the average of $77.60 \%$, with a standard deviation of about $34.56 \%$, indicating a persistent rise in price level. On the other hand, the growth of unemployment in the region averaged at about $9.53 \%$, with a standard deviation of about $8.18 \%$. This statistic validates the argument that unemployment and inflation grow in a disproportionate rate in any economy.

Table 1. Summary Statistics.

\begin{tabular}{llllll}
\hline Variables & Obs & Mean & Std. Dev. & Min. & Max \\
\hline Un & 580 & 9.531 & 8.183 & 0.6 & 39.3 \\
Infl & 604 & 77.609 & 34.558 & 0 & 250.62 \\
\hline
\end{tabular}

Source: author's computation.

\subsection{Panel Unit Root Test}

Before conducting the test for panel cointegration, there is a need to ensure that both variables are integrated of order one I (1). To achieve this panel unit root tests analysis was carried out and Levin - Lin - Chu unit root test technique was employed. The panel unit root results are presented in Table 2 .

Table 2. Panel Unit Root Tests: Levin - Lin -Chu (LLC)*

\begin{tabular}{lllll}
\hline & Levels & First Difference & \\
\hline Variable & Individual effects & Individual effects and linear trends & Individual effects & Individual effects and linear trends \\
\hline$U n_{i t}$ & -1.8214 & $-0.2410^{* *}$ & $-7.4172^{* * *}$ & $-6.1420^{* *}$ \\
$I n f l_{i t}$ & $-6.4486^{* *}$ & -0.5919 & $-5.0124^{* *}$ & -2.1214 \\
\hline
\end{tabular}

*Source: the authors computation using Stata software ** indicates significance at 0.05 level ** indicates significance at 0.01 level.

The minor data instability issues notwithstanding, the LLC test for unemployment rate could not reject the null hypothesis of unit roots at levels, with and without linear trends, but the test rejected the null hypothesis of unit root in the case of first difference, with and without trend. On the other hand, LLC test for the inflation rates showed that the variable was stationary both at levels, and at first difference, but without trend in both cases. The implication of this unit root tests result for analysis, is that, the variables (unemployment rate and inflation rate) do not seem to have integrating property that would warrant the application of panel cointegration analysis.

The reason for this conclusion is based on the fact that, the two variables, though stationary, reflect their stationarity properties in different order of integration. Though the results seems to present a very strong evidence of a stationary process of the variables modelled in this paper, therefore, the divergence in the integration order would not make for the application of panel cointegration analysis. This therefore informed the decision to drop further application of panel cointegration analysis, in examining the long run relationship between the two variables - inflation rate and unemployment rate.

\subsection{Panel Data Analysis}

As was earlier stated in the this paper, Fixed Effect (FE) panel data analysis technique was considered appropriate for the analysis of the data, based on the underlining arguments in the literature. It has been argued that using FE is 
intuitively the same as allowing a different intercept for each cross-sectional unit, and Two-Way Fixed Effect technique has been proven a more appropriate approach overtime. However, for a reliable and a more concrete conclusion, the
One-Way Fixed Effect, Two-Way fixed effect and Random Effect (RE) were carried and the results are presented in Table 3 .

Table 3. Panel Data Analysis: One-Way Fixed Effect, Two-Way Effect and Random Effect Models.

\begin{tabular}{|c|c|c|c|}
\hline & One-Way Fixed Effect & Two-Way Fixed Effect & Random Effect \\
\hline constant & $124.51(13.07)^{*}$ & $73.43(9.98)^{*}$ & $80.19[23.68] * \dagger$ \\
\hline$U n_{i t}$ & $-5.24(-5.23)^{*}$ & $-0.82(-1.45)$ & $-0.54[-2.05]^{* * \dagger}$ \\
\hline Infl $_{i t-1}$ & $0.39(7.74)^{*}$ & $0.28(5.46)^{*}$ & $0.41[8.03]^{* \dagger}$ \\
\hline Adj. $R^{2}$ & 0.022 & 0.642 & 0.093 \\
\hline$F_{(2,545),(21,526)}$ & $48.31 *$ & $76.61 *$ & Wald $=69.88^{*}$ \\
\hline$F_{(28,545) ;(21,526)}: u \_i=0$ & $4.24 *$ & $10.68 *$ & \\
\hline Sigma_e & 28.13 & 15.42 & 28.13 \\
\hline
\end{tabular}

Dependent Variable: $\operatorname{In} f l_{i t}$.

Values in parentheses are t-statistics $\uparrow$ Values in bracket are $z$-statistics * indicates significance at 0.01 level.

$* *$ indicates significance at 0.10 level.

From the results reported in Table 3, the One-Way FE showed a trade-off between inflation rate and unemployment rate in Sub-Saharan African, with a very strong and significant relationship. The result showed that a $1 \%$ rise unemployment rate in Sub-Saharan Africa will result in about a $5.24 \%$ fall in inflation rate. However, a closer look at the result showed that, though the model was generally stable (that is, the F-statistics were significant), the $\mathrm{R}^{2}$ and the adjusted $\mathrm{R}^{2}$ were both very poor. They stood at 0.150 and 0.022 respectively, implying that only $15 \%$ of the total variation can be explained by the model, even when a lag of the dependent variable had been introduced. This showed that not taking time effect into consideration in the analysis may weaken the outcome of the analysis, thus the result may be misleading, though Bhattarai (2004) considered time effect as "less important" in the case of OECD countries. He, however, identified a similar result for the OECD countries. Furuoka and Munir (2009) and Wooldridge (2013) corroborate this argument.

On the other hand, the Two-Way FE evaluated both the country and time effects in the model. The F-statistic indicated that the model was very stable at $76.61 \%$ and at $1 \%$ significant level. Though the signs of the coefficients indicated a seeming trade-off between inflation rate and unemployment rate in Sub-Saharan Africa, the result showed a statistically insignificant relationship amongst the duo variables. However, the $\mathrm{R}^{2}$ and the adjusted $\mathrm{R}^{2}$ showed a very significant improvement. The result showed that $\mathrm{R}^{2}$ and adjust $R^{2}$ improved from 0.150 and 0.022 respectively, in the case of One-Way FE, to 0.753 and 0.642 respectively, in the case of Two-Way FE. This implies that about $75 \%$ of the total variation can be explained by the model, drawing a strong case for informed conclusion, given the strength of its overall explanatory power. This outcome, first, agree with argument in the literature (e.g. Wooldridge, 2013) on TwoWay FE model as a batter choice, in this circumstance, for its ability to take country effect and time effect into consideration in the estimation. The second fact is that, it gives a more robust and revealing explanation to the panel data interactions across the sample space.

Furthermore, we also estimated the panel data for inflation rate and unemployment rate, using Random Effect (RE) technique, at least for the purpose of comparing and validating our outcome. The result was not of any different from that of One-Way FE, in terms of implications. The result reflected a trade-off between inflation rate and unemployment rate in Sub-Saharan Africa, and was statistically significant at $1 \%$ level, with the coefficient of $0.54 \%$, showing that a $1 \%$ rise in unemployment rate will bring about a $0.54 \%$ decline in the rate of inflation in SubSaharan African economies, ceteris paribus. Again, the result may be misleading. Though the wald test result showed that the model is properly structured and is stable, the coefficient of determination $\left(\mathrm{R}^{2}=0.116\right)$ and the Adjusted coefficient of determination (Adj. $\mathrm{R}^{2}=0.093$ ) indicated a poor fit for the model. This outcome, again, validated the choice of TwoWay FE as a better approach for the estimation of the panel data employed in this study.

\subsection{Discussion of Findings}

As has been identified, the implication of the above findings is that there is no trade-off between the two variables in Sub-Saharan Africa - this is in the light of the Two-way FE result. That is, Phillip's Curve could not be established in the region, drawing from the outcome of this study. This agrees with the findings of Furuoka and Munir (2009) for selected five Asian countries. The found no common Phillip's Curve for the Asian countries of Malaysia, Indonesia, Thailand, the Philippines and Singapore. A number of factors may be responsible for this outcome. First, distortions in the data generation and collection from the different economies could impact on the associated results, despite the clean-up efforts. The generation of these distortions may arise from data collection technique, sample size and space selection, tools of data collection, and so on.

The state of the result may also not be unconnected with the differentials in the wellbeing of the economies included 
in our sample space. The fact that most of the Sub-Saharan economies share some basic treats in common notwithstanding, there are still great disparities among these economies, especially in terms of the rates of unemployment and inflation, and these again, are products of some basic internal disparities, which may be economic, social and/or political. Thirdly, the difference in economic policies and priorities (that is, the differences in how the countries and their people form expectations) may also influence the outcome of analysis to a large extent.

It is therefore important to mention that the usage of the outcome of this study - in any of the economies included in sample - for policy measures, should be done with caution and under a very controlled policy dimensions. The reasons for the caution are obvious. It is clear that Philip's Curve hypothesis does not seems to hold, homogeneously, across the region. This, as was earlier mentioned, may be due to the heterogeneous (rational) interactions of these economies in their peculiar circumstances, as it relates to these macroeconomic indices - unemployment and inflation rates. Though there are regional similarities, these economies set priorities based on their peculiar circumstances and form expectations as such, may be for a common goal of meeting their aggregate demand targets, for instance.

The significance that the unemployment-inflation rates portrayed in their relationship, despite the size of the $\mathrm{R}^{2}$, seems to depict and inconclusive outcome, but as seen in the literature, the inclusion of time effect, and the fact that using FE is instinctively the same as allowing a different intercept for each cross-sectional unit, made the Two-way FE obviously appealing and reasonably reliable, hence the decision to tailor the extensive conclusion of this paper on its outcome.

\section{Conclusion}

In this study, we attempted the assessment of the validity of the Philip's curve hypothesis in the Sub-Saharan African region. We employed a panel data technique of analysis, drawing data from twenty-nine countries in the region. The data spanned 24 years (1991 to 2015). The inflation rate was captured using the consumer price index (CPI - its log first difference), while unemployment rate was measured by total unemployment (as a percentage of total labour force, a national estimate) for these countries. Using a panel data analysis technique, our result showed that there was no significant relationship between inflation rate and the rate of unemployment. The result invalidated the existence of the common Philip's Curve (that is, unemployment-inflation trade-off) in the Sub-Saharan African region. However, it was advised that the use of the outcome of this study, for policy measures, should be done cautiously, as the result may have been influenced by some distortions arising from heterogeneous rationalities that may have been inherent in the data.

\section{Appendix}

Table 4. List of Sub-Saharan African Countries Included in the Sample.

\begin{tabular}{llll}
\hline $\mathbf{( 1 )}$ & $\mathbf{( 2 )}$ & $\mathbf{( 3 )}$ & $\mathbf{( 4 )}$ \\
\hline Angola & Benin & Botswana & Burkina Faso \\
Cameroon & CAR & Congo DR & Côte d'Ivoire \\
Equatorial Guinea & Ethiopia & The Gambia & Ghana \\
Guinea-Bissau & Kenya & Lesotho & Malawi \\
Mauritania & Mauritius & Madagascar & Mozambique \\
Niger & Nigeria & Rwanda & Senegal \\
Swaziland & Tanzania & Togo & Uganda \\
Zambia & & & \\
\hline
\end{tabular}

\section{References}

[1] Bahmani, M. and Miteza, I. (2004). Panel Cointegration and Productivity Bias Hypothesis. Journal of Economic Studies 31 (5), 448-456.

[2] Bahmani-Oskooee, M. and Miteza (2005). Panel cointegration and Productivity Bias Hypothesis, Journal of Economic Studies, 31 (5), 1061-1071.

[3] Batini, N., Jackson, B. and Nickell, S. (2005). An Openeconomy New Keynesian Phillips Curve for the UK, Journal of Monetary Economics, 52, 1061-1071.

[4] Bhattarai, K. R. (2004) Unemployment-inflation Trade-offs in OECD Countries: Lessons from Panel Data and Theories of Unemployment. Working Paper (draft), Business School, University of Hull, United Kingdom.

[5] Blanchard, O. (2009). Macroeconomics, Pearson Education Inc., USA, $5^{\text {th }}$ Edition.

[6] Cashell, B. W. (2004). Inflation and Unemployment: What is the Connection? CRS RL 30391, 1-19.

[7] Debelle, G. and Vickery, J. (1998). Is the Phillips Curve a Curve? Some Evidence and Implications for Australia, The Economic Record, 74, 384-398.

[8] DiNardo, J. and Moore, M. (1999). The Phillips Curve is Back? Using Panel Data to Analyze the Relationship between Unemployment and Inflation in an Open Economy, NBER Working Paper 7328, 1-27.

[9] Friedman, M. (1968). The Role of Monetary Policy, American Economic Review, LVIII, 1.

[10] Furuoka, F. and Munir, Q. (2009). "Phillips Curve" in Selected Asean Countries: New Evidence from Panel Data Analysis, Sunway Academic Journal, 6, 89-102.

[11] Gordon, R. J. (1971). Price in 1970: The Horizontal Phillips Curve. Brookings Papers on Economic Activities, (3), 449 458.

[12] Hart, R. A. (2003). Overtime Working, the Phillips Curve and the Wage Curve, The Manchester School, 71 (2), 97-112.

[13] Hendry, D. F. (1993). Econometrics Alchemy or Science, Basil Blackwell.

[14] Hogan, V. (1998). Examining the Recent Behaviour of Inflation and Unemployment, IMF Working Papers, 145.

[15] Im, K. S., Pesaran, M. H. and Shin, Y. (2003). Testing for Unit Roots in Heterogeneous Panels. Journal of Econometrics, 115, 53-74. 
[16] Islam, F., Hassan, K., Mustafa, M. and Rahman, M. (2003). The Empirics of U. S. Phillips Curve: A Revisit, American Business Review, 20 (1), 107-112.

[17] King, R. G. and Watson, M. W. (1994). The Post-War U. S. Phillips Curve: A Revisionist Econometric History, CarnegieRochester Conferences Series on Public Policy, 41, 157-219.

[18] Lucas, R. E. (1976). Econometric Policy Evaluation: A Critique. Carnegie Rochester Conference Series on Public Policy, 1, 19-46.

[19] Lucas, R. E. and Rapping, L. A. (1969). Real Wages, Employment and Inflation, Journal of Political Economy, 77 (5), 721-754.

[20] Maddala, G. S. and Wu, S. (1999). A Comparative Study of Unit Root Tests with Panel Data and a New Simple Test. Oxford Journal of Economics and Statistics, Special Issue. 631-652.

[21] Mankiw, N. G. (2000). Macroeconomics, Worth Publishers, USA, $4^{\text {th }}$ Edition.

[22] Ola-David, O. and Oluwatobi, S. (2012). Output and Unemployment Relationship: How Applicable Is the Okun's Law to Nigeria? http://dx.doi.org/10.2139/ssrn.2512898.

[23] Onwioduokit, E. A. (2006). Character of Unemployment in Nigeria and its links with the Macroeconomy, West African Monetary Institute, Accra, Ghana: The Nigerian Economic Society, Selected Papers for Annual Conference.
[24] Orji, A., Orji, O. I. and Okafor, J. C. (2015). Inflation and Unemployment Nexus in Nigeria: Another Test of the Phillips Curve, Asian Economic and Financial Review, 5 (5), 766778.

[25] Pedroni, P. (1999). Critical Values for Cointegration Tests in Heterogeneous Panels with Multiple Regressors. Oxford bulletin of Economics and Statistics. Special Issue. 635-670.

[26] Pedroni, P. (2004). Panel Cointegration: Asymptotic and Finite Sample Properties of pooled time Series Tests with Application to the PPP Hypothesis. Econometric theory. 20, 597-670.

[27] Phelps, E. S. (1968). Money-Wage Dynamics and LabourMarket Equilibrium, Journal of Political Economy, 76, 678710 .

[28] Phelps, E. S. (1994). Structural Slumps, Harvard University Press.

[29] Phillips, A. W. (1958). The Relationship between Unemployment and the Rate of Change of Money Wage Rates in the United Kingdom, Economica, 25: 258-299.

[30] Samuelson, P. A. and Solow, R. M. (1960). Analytical Aspect of Anti-Inflation Policy, American Economic Review, 50: 177194.

[31] Solow, R. W. (1970). Discussion of RJ Gordon's Recent Acceleration of Inflation and its Lessons for the Future, Brookings Papers on Economic Activities, 1, 42-46. 